\title{
The Evolving Adjuvant Treatment Landscape in Patients with Early Breast Cancer
}

\author{
Hina Khan ${ }^{1}$ and Jesus Anampa2* \\ ${ }^{1}$ Department of Medical Oncology, Albert Einstein College of Medicine/Montefiore Medical Center, Bronx, New York 10461, USA \\ ${ }^{2}$ Department of Medical Oncology, Albert Einstein College of Medicine/Montefiore Medical Center, New York, USA
}

Keywords: Breast cancer; Adjuvant chemotherapy; Early breast cancer; Chemotherapy; Anthracyclines; Taxanes review

Breast cancer is the most common cancer in women in the USA and second only to lung cancer in mortality $[1,2]$. It is estimated that there will be 231,840 new cases of invasive breast cancer and 40,290 deaths from the disease in 2015. While the incidence of breast cancer has increased steadily in the United States through the 1980s, it has now stabilized at about 125 cases per 100,000 per year $[3,4]$. Breast cancer survival has significantly improved over the years, reflecting advances in effective local and systemic therapy. Moreover, adjuvant systemic therapy reduces the risk of distant recurrence presumably by treating micro-metastatic disease that may not be clinically evident at the time of definitive local therapy. While the benefit from endocrine and HER-2 directed therapy is predicted by the expression of their respective receptors [5,6], predicting response to chemotherapy remains a challenge. Several multi parameter gene expression assays have now been developed, which provide further prognostic information and more importantly predict benefit from adjuvant chemotherapy [5]. These assays will help tailor therapy towards patients who will derive greatest benefit from chemotherapy $[6,7]$.

Endocrine therapy reduces the risk of breast cancer recurrence in hormone receptor positive disease, when used with or without chemotherapy. In 1982, 2-year adjuvant tamoxifen treatment was shown to reduce the risk of recurrence [8] and improve survival [9], with subsequent studies revealing that five-year tamoxifen therapy was more effective than shorter durations. Five-year tamoxifen decreased recurrence by about $40 \%$ and breast cancer mortality by $30 \%$, interestingly the effect of tamoxifen was present not only during therapy (1-5 years) but also after tamoxifen was discontinued(carryover effect) [10]. Tamoxifen risk reductions were substantial and consistent for women in each age range (including post-menopausal woman) [10]. First generation Aromatase inhibitors were too toxic in pivotal clinical trials and further development of third generation Aromatase inhibitors showed better toxicity profile and subsequently were found to improve DFS and OS when compared to tamoxifen in postmenopausal women [11,12]. Hormone receptor positive disease is known to have recurrence even beyond 5 years of diagnosis; therefore clinical trials with longer endocrine therapy were developed [13]. Extended adjuvant therapy for up to 10 years was shown to be more effective than 5 years of therapy, including sequential tamoxifen followed by an aromatase inhibitor [14], or tamoxifen for up to 10 years [15]. Finally, in premenopausal women at high risk for recurrence, ovarian suppression plus an aromatase inhibitor was shown to be more effective than tamoxifen $[16,17]$.

Recently published article by Anampa et al. summarized the important landmark trials and recent advances in the evolution of adjuvant chemotherapy for early breast cancer [18]. The national surgical adjuvant breast and bowel project (NSABP) B-01 trial initiated in 1958, the first randomized trial evaluating adjuvant chemotherapy in breast cancer after local therapy, revealed that thiotepa significantly decreased recurrence rate in pre-menopausal women with $\geq 4$ positive axillary lymph nodes [19]. Meanwhile, several combination regimens were being used for lymphoma with good outcomes such as MOPP regimen (mechlorethamine, vincristine, procarbazine and prednisone) that were used to treat patients with Hodgkin's disease [20], leading to the development of CMF (cyclophosphamide, Methotrexate and 5-FU) regimen with the intent to resemble the highly active MOPP regimen.

Bonadonna et al. from the Istituto Nazionale Tumori in Milan, Italy showed that CMF used after surgical resection significantly reduced the risk of breast cancer recurrence (HR 0.70 ) and mortality (HR 0.76) [21,22], leading to a new strategy in breast cancer management. In 2001, a national institute of health (NIH) consensus panel in the USA concluded that chemotherapy should be recommended to the majority of women with localized breast cancer regardless of lymph node, menopausal or hormone receptor status [23].

Anthracyclines were found to have significant effect in breast cancer cells. Therefore initial trials evaluated the combination of doxorubicin $60 \mathrm{mg} / \mathrm{m}^{2}$ plus cyclophosphamide $600 \mathrm{mg} / \mathrm{m}^{2}$ (AC) given every three weeks for total of four cycles, and at least two large clinical trials found similar DFS and OS when compared to six cycles of CMF in patients with node positive and negative disease [24,25].

Paclitaxel and docetaxel are the most common used taxanes in the management of breast cancer. Sequential addition of four cycles of every3-week paclitaxel to four cycles of AC was found to have improved DFS $(\mathrm{HR}=83)$ and $\mathrm{OS}(\mathrm{HR}=0.82)$ [26]. Docetaxel was found to be a more potent microtubule inhibitor than paclitaxel, therefore clinical trials evaluated docetaxel combined sequentially versus concurrently with doxorubicin/cyclophosphamide. Sequential docetaxel-AC improved DFS $(\mathrm{HR}=0.83)$ compared to concurrent docetaxel-AC [27].

Adjuvant! Online is a web-based decision aid used by many clinicians to understand the potential benefits of adjuvant therapy (endocrine or cytotoxic). Adjuvant! classifies chemotherapy regimens as first, second and third generation [28]. Third-generation (anthracycline and taxane containing) regimens are commonly used in patients with high recurrence-risk, given superior efficacy when compared to first or second generation regimens. First and second generation regimens still have an important role in clinical practice, such as situations when anthrayclines need to be avoided or for tumors with low/intermediate recurrence-risk. Dose density and intensity have been evaluated for

*Corresponding author: Jesus Anampa, Assistant Professor Medicine Department of Medical Oncology. Albert Einstein College of Medicine/Montefiore Medical Center, Bronx New York 10461, E-mail: janampa@montefiore.org

Received January 25, 2016; Accepted January 27, 2016; Published February 03, 2016

Citation: Khan H, Anampa J (2016) The Evolving Adjuvant Treatment Landscape in Patients with Early Breast Cancer. Mol Biol 5: e121. doi:10.4172/2168$9547.1000 \mathrm{e} 121$

Copyright: $\odot 2016 \mathrm{Khan} \mathrm{H}$, et al. This is an open-access article distributed under the terms of the Creative Commons Attribution License, which permits unrestricted use, distribution, and reproduction in any medium, provided the original author and source are credited. 
different chemotherapy regimens. The optimal Taxane schedule was evaluated by the ECOG E1199 trial, in which patients treated with AC $\times 4$ were assigned to receive paclitaxel or docetaxel every three weeks for four doses or weekly for 12 doses using a $2 \times 2$ design. After 12.1year follow-up, DFS was significantly improved and OS marginally improved for both the weekly paclitaxel arm (HR 0.84, $\mathrm{p}=0.011$ and HR $0.87, \mathrm{p}=0.09$, respectively) and every-3-week docetaxel arm (HR $0.79, \mathrm{p}=0.001$ and HR $0.86, \mathrm{p}=0.054$, respectively) when compared to the control arm (every-3-week paclitaxel). Although weekly paclitaxel improved DFS and OS (HR 0.69, p=0.010 and HR 0.69, p=0.019, respectively) in triple negative breast cancer, no experimental arm improved OS for hormone receptor positive, HER2 non-overexpressing breast cancer [29].

One major challenge with the evolution of the adjuvant chemotherapy in breast cancer is to decide about whether or not to use it; as despite the reduced recurrence rates and mortality it is associated with considerable adverse effects. Gene expression profiling is an emerging technology for identifying genes whose activity may be helpful in assessing disease prognosis and guiding therapy. In recent years, several multiparameter gene expression profiling assays have been shown to provide prognostic information in patients with ERpositive breast cancer [6,7], these assays include the Oncotype $\mathrm{DX}^{\circ}$ (Genomic Health, Inc., Redwood City, CA), MammaPrint ${ }^{\circledR}$ (Agendia, Inc. USA, Irvine, CA), Prosigna (Nanostring Technologies, Seattle, WA), and Breast Cancer Index ${ }^{\text {su }}$ (bioTheranostics, Inc., San Diego, CA). TAILORx, MINDACT, RxPONDER, and OPTIMA trials are evaluating the incorporation of multiparameter gene expression assays into clinical decision making to tailor adjuvant treatment among patients with breast cancer.

HER2 oncogene expression is present in about 25\% patients with breast cancer [30]. Trastuzumab, a monoclonal antibody which binds to HER2 domain IV initially approved in 2006 after analysis of NSABP B31 and NCCTG N9831 studies, shows substantially decreased risk of recurrence in patients with HER2 overexpressing node-positive or high-risk node-negative breast cancer [31-34]. Addition of trastuzumab to sequential anthracycline/cyclophosphamide-taxane was associated with about a 3-5\% risk of cardiac toxicity [31-33], while the combination of trastuzumab with non-anthracycline regimens (e.g. carboplatin/ docetaxel), was associated with lower rates of cardiac toxicity [34]. Subsequent studies demonstrated that one year of trastuzumab was more effective than 6 months [35], but two years of therapy was no more effective than one year [36]. Pertuzumab, a monoclonal antibody which binds to HER-2 extracellular domain II, has shown improved complete pathological response rates when used in the neoadjuvant setting in NEOSPHERE/TRYPHAENA trials [37], and currently being evaluated in the adjuvant setting as per APHINITY trial. The current version of NCCN guidelines allow adjuvant Petuzumab-containing regimens in patients with high risk HER2 positive disease (T2 or greater, and N1 or greater) Bone is one of the most common sites of breast cancer recurrence, and bisphosphonates have been shown to exert anticancer effects and alter the microenvironment. Clodronate and zolendronic acid were used as adjuvant therapy in patients with early breast cancer. A recent meta-analysis included 17709 women treated with adjuvant bisphosphonates and revealed a significant improvement in bone recurrence in the entire study population. ( $\mathrm{HR}=0.83)$, subgroup analysis showed that adjuvant bisphosphonates improved also distant recurrence and breast cancer mortality ( $\mathrm{HR}=0.82)$ among postmenopausal women [38].

Denosumab, a fully human IgG2 monoclonal antibody that binds to RANK ligand, is an essential mediator of osteoclast activity. The ABCSG-18 trial evaluated the role of adjuvant denosumab $60 \mathrm{mg}$ subcutaneously every 6 months versus placebo in 3420 patients with early hormone-receptor positive breast cancer receiving aromatase inhibitors. Patients in the denosumab group had significant decrease in fracture risk $(\mathrm{HR}=0.50, \mathrm{p}<0.0001)$. In the recent San Antonio Breast Cancer Symposium 2015, the study group reported an improved DFS (HR=0.816, 95\%CI 0.66-1.00, p 0.0515) favoring the denosumab arm.

In conclusion, medical oncologists need to carefully select patients for adjuvant therapy based on tumor-specific factors (tumor size, axillary node metastasis) and tumor biology (ER/PR and HER2 expression, multiparameter gene expression assays), and patient specific factors such as age, comorbidities and patient preference. A risk classification and potential therapeutic options for each risk category are proposed in Table 1. Improvements in adjuvant cytotoxic regimens have contributed to declining breast cancer mortality rates in recent years, and ongoing clinical trials may identify subgroups with greatest benefits from such therapy. Further results on clinical trials evaluating HER2 directed therapies, bisphosphonates and denosumab are expected to increase the available therapeutic options for management of patients with early breast cancer.

\begin{tabular}{|c|c|c|c|}
\hline \begin{tabular}{|c|} 
Recurrence Risk \\
Category and Definition
\end{tabular} & $\begin{array}{l}\text { Recommended Regimens: } \\
\text { ER positive, HER2-Negative }\end{array}$ & $\begin{array}{l}\text { Recommended Regimens: } \\
\text { ER/PR negative, HER2-Negative }\end{array}$ & $\begin{array}{l}\text { Recommended Regimens: } \\
\text { HER2-Positive }\end{array}$ \\
\hline \multicolumn{4}{|c|}{ Very Low Risk } \\
\hline - Node-Neg, T1a & No chemotherapy & No chemotherapy & No chemotherapy \\
\hline \multicolumn{4}{|c|}{ Low Risk } \\
\hline - Node-Neg, T1b & $\begin{array}{l}\text { Consider } 2^{\text {nd }} \text { generation chemotherapy } \\
\text { regimen if } R S \text { is high }\end{array}$ & $\begin{array}{c}\text { Consider } 2^{\text {nd }} \text { generation chemotherapy } \\
\text { regimen }\end{array}$ & Consider weekly paclitaxel $+\mathrm{H}$ \\
\hline - Node-Neg, T1c, & $\begin{array}{l}2^{\text {nd }} \text { generation chemotherapy regimen if RS is } \\
\text { high (or consider if intermediate) }\end{array}$ & $2^{\text {nd }}$ generation chemotherapy regimen & Weekly paclitaxel $+\mathrm{H}$ or $\mathrm{TCH}$ \\
\hline \multicolumn{4}{|c|}{ Moderate Risk } \\
\hline - Node-Neg, T2 & $\begin{array}{c}2^{\text {nd }} \text { or } 3^{\text {rd }} \text { generation chemotherapy regimen if } \\
R S \text { intermediate-high }\end{array}$ & $3^{\text {rd }}$ generation chemotherapy regimen & $\mathrm{AC}-\mathrm{T}+\mathrm{H}$ or $\mathrm{TCH}+/-\mathrm{P}$ \\
\hline $\begin{array}{l}\text { High Risk } \\
\text { - +Pos Nodes or T3 }\end{array}$ & $\begin{array}{c}3^{\text {rd }} \text { generation chemotherapy regimen if } \\
R S \text { intermediate-high (or } 4+\text { positive nodes } \\
\text { irrespective of } R S \text { ) }\end{array}$ & $3^{\text {rd }}$ generation chemotherapy regimen & $\mathrm{AC}-\mathrm{T}+\mathrm{H}$ or $\mathrm{TCH}+/-\mathrm{P}$ \\
\hline
\end{tabular}

TCH: Docetaxel, Carboplatin, Trastuzumab; T: paclitaxel; AC: Doxorubicin, Cyclophosphamide; H: Trastuzumab, P: Pertuzumab. Neg: Negative. Pos: Positive; RS: Recurrence score.

Table 1: Commonly recommended adjuvant chemotherapy regimens [18]. 
Citation: Khan H, Anampa J (2016) The Evolving Adjuvant Treatment Landscape in Patients with Early Breast Cancer. Mol Biol 5: e121. doi:10.4172/2168-9547.1000e121

Page 3 of 4

\begin{tabular}{|c|c|c|}
\hline Year & Event & Reference \\
\hline 1894 & Halsted introduced radical mastectomy for breast cancer. & Ann Surg. 1894; 20:497-555. \\
\hline 1950s & Anthracyclines isolated from gram-positive Streptomyces in Indian soil samples. & Drugs, 1997. 54(4): 1-7. \\
\hline 1968 & NSABP B-01. Thiotepa after radical mastectomy decreased recurrence rate and OS. ${ }^{a}$ & Fisher, et al. [19] \\
\hline 1969 & Paclitaxel is isolated after an exploratory plant screening program. & Med Res Rev, 1998; 18: 315-331. \\
\hline 1974 & Doxorubicin shows activity against breast cancer cells. & Br J Cancer. 1974; 29: 114-116. \\
\hline 1975 & Melphalan shows improved DFI as adjuvant after mastectomy. ${ }^{b}$ & N Engl J Med 1975; 292:117-122 \\
\hline 1976 & CMF $\times 12$ shows decreased rate failure compared to control (no chemotherapy). ${ }^{c}$ & Bonadonna, et al. [22] \\
\hline 1979 & CMF $\times 6$ vs CMF $\times 12$ have similar DFS and OS. ${ }^{d}$ & Cancer Clin Trials 1979; 2: 285-292. \\
\hline 1979 & Horwitz demonstrated mechanism of action of paclitaxel. & Med Res Rev, 1998. 18: 315-31. \\
\hline 1983 & Tamoxifen improves survival in patients with early breast cancer & Baum, et al. [9] \\
\hline 1990 & NSABP B-15: AC $\times 4$ vs CMF $\times 6$ revealed similar OS or DFS in node + disease. ${ }^{e}$ & Fisher, et al. [24] \\
\hline 2001 & NSABP B-23. No difference in OS for AC $\times 4$ and CMF $\times 6$ in node negative patients. ${ }^{f}$ & Fisher, et al. [25] \\
\hline 2001 & $\mathrm{NIH}$ consensus recommended adjuvant chemotherapy for patients with early breast cancer. & Abrams [23] \\
\hline 2001 & Five years of adjuvant Tamoxifen therapy is more effective than shorter durations. ${ }^{9}$ & $\begin{array}{l}\text { Cochrane Database Syst Rev, 2001; } 1 \text { : } \\
\text { CD00486 }\end{array}$ \\
\hline 2003 & CALGB 9741: Dose density improves DFS and OS. ${ }^{h}$ & J Clin Oncol, 2003; 21: 1431-9 \\
\hline 2003 & INT 0148/CLGB 9344 : Sequential paclitaxel after AC improved DFS and OS.' & Henderson, et al. [26] \\
\hline 2004 & Oncotype Dx validated in NSABP B-14 /B-20 studies. & N Engl J Med, 2004; 351: 2817-2826. \\
\hline 2005 & Trastuzumab combined to paclitaxel after AC, improves DFS and OS in HER2 overexpressing disease. ${ }^{j}$ & Romond EH, et al.[31] \\
\hline 2005 & Aromatase inhibitors more effective than Tamoxifen in postmenopausal women. ${ }^{k}$ & $\begin{array}{l}\text { Breast International Group 1-98 } \\
\text { Collaborative [12] }\end{array}$ \\
\hline 2006 & US oncology $9735:$ TC $\times 4$ has improved DFS compared to AC $\times 4 !$ & J Clin Oncol. 2006; 24: 5381-5387. \\
\hline 2008 & ECOG 1199: Weekly sequential paclitaxel after AC improves DFS and OS. ${ }^{m}$ & N Engl J Med, 2008; 358: 1663-1671. \\
\hline 2013 & One year adjuvant trastuzumab is as effective as 2 years in HER2 overexpressing disease. ${ }^{n}$ & Goldhirsch A, et al. [36] \\
\hline 2013 & $\begin{array}{l}\text { Pertuzumab combined with trastuzumab based chemotherapy improves } p C R \text { in HER2 locally advanced breast } \\
\text { cancer }\end{array}$ & Schneeweiss, et al. [37] \\
\hline 2013 & Extended adjuvant Tamoxifen up to 10 years more effective than 5 years therapy..$^{\circ}$ & Davies, et al. [15] \\
\hline 2014 & $\begin{array}{l}\text { Ovarian suppression and aromatase inhibitor (exemestane) more effective than tamoxifen and ovarian suppression } \\
\text { in premenopausal women. }{ }^{p}\end{array}$ & Pagani, et al. [17] \\
\hline
\end{tabular}

DFI: Disease-free interval; OS: Overall survival; DFS: Disease-free survival; RFS: Recurrence-free survival; EFS: vent-free survival; DDFS: Distant disease-free survival; pCR: Pathological complete response;

a. Thiotepa improved 5 -year survival rate $(57 \%$ vs $24 \%, p<0.05)$ in pre-menopausal women with four or more positive LN compared to placebo. b. Treatment failure $22 \%($ placebo) and $9.7 \%$ (Melphalan), $p=0.01$. Disease-free interval showed statistically significant difference $(p=0.02)$ in favor of Melphalan. c. Treatment failure ( 25 vs $5.3 \%$, $\mathrm{p}<0.00001$ ) for control and CMF respectively. d. 3-year RFS survival was $85.4 \%$ (CMF x12) compared to $82.6 \%$ (CMF x6), $P=0.29 .0 S$ 86.2\% vs. 85.1\%, $P=0.49$. e. No difference in 3-year DFS ( $P=0.5)$, distant disease-free survival (DDFS, $P=0.5)$ or survival $(P=0.8)$ between both groups. $f$. No significant difference for $C M F$ and $A C$ in $R F S$ ( $87 \%$ both groups, $\mathrm{P}=0.9)$, EFS $(83 \%$ and $82 \%, \mathrm{P}=0.6)$, or survival $(89 \%$ and $90 \%, \mathrm{P}=0.4)$. g. With 5 years of Tamoxifen use absolute improvement in 10 -year survival was $10.9 \%$ for node-positive and $5.6 \%$ for node-negative, compared to 1 and 2 years. $h$. Dose-dense improved $D F S(R R=0.74 ; P=.010)$, and $O S$ (RR=0.69; $P=.013)$. There was no difference in either DFS or OS between the concurrent and sequential schedules. $\mathrm{i}$. Hazard reductions from adding paclitaxel to AC were $17 \%$ for recurrence (adjusted Wald X2 P=.0023; unadjusted Wilcoxon $\mathrm{P}=.0011$ ) and $18 \%$ for death (adjusted $\mathrm{P}=.0064 ;$ unadjusted $=.0098$ ). j. DFS HR 0.48, $\mathrm{P}<0.0001, \mathrm{OS}$ HR $0.67, \mathrm{p}=0.015$, favoring Trastuzumab vs control.

k. Compared to tamoxifen, letrozole significantly reduced the risk of distant recurrence; HR 0.73, 95\% Cl: 0.7-0.93, P = 0.003). I. 5-year DFS TC (86\%) compared with $\mathrm{AC}(80 \%) ; \mathrm{HR}=0.67 ; 95 \% \mathrm{Cl}, 0.50$ to $0.94 ; \mathrm{P}=0.015 \mathrm{~m}$. As compared with patients receiving q-3-week paclitaxel, the odds ratio for 5 -year $\mathrm{DFS}$ was 1.27 among those receiving weekly paclitaxel $(P=0.006)$, OS also favored weekly paclitaxel (odds ratio, 1.32; $P=0.01$ ). $n$. One year of adjuvant trastuzumab provided comparable DFS and OS benefits as compared to 2 years. o. Continuing Tamoxifen up to 10 years further reduced recurrence and mortality, as compared to 5 years therapy. p. Adjuvant exemestane with ovarian suppression significantly reduced recurrence compared to tamoxifen with ovarian suppression; with DFS at 5-years: $91.1 \%$ in exemestane arm compared to $87.3 \%$ in Tamoxifen arm.

Table 2: Timeline of adjuvant therapy for breast cancer

\section{References}

1. Jemal A, Center MM, DeSantis C, Ward EM (2010) Global patterns of cancer incidence and mortality rates and trends. Cancer Epidemiol Biomarkers Prev 19: 1893-1907.

2. Torre LA, Bray F, Siegel RL, Ferlay J, Lortet-Tieulent J, et al. (2015) Global cancer statistics, 2012. CA Cancer J Clin 65: 87-108.

3. Siegel RL, Miller KD, Jemal A (2015) Cancer statistics. CA Cancer J Clin 65: 5-29.

4. Howlader N, Krapcho M, Garshell J, Miller D, Altekruse SF, et al. (2011) http:// seer.cancer.gov/csr/1975_2011/.

5. Hammond MEH, Hayes DF, Wolff AC, Mangu PB, Temin S (2010) American Society of Clinical Oncology/College Of American Pathologists guideline recommendations for immunohistochemical testing of estrogen and progesterone receptors in breast cancer. J Clin Oncol 16: 2784-95.

6. Sparano JA, Fazzari M, Kenny PA (2010) Clinical application of gene expression profiling in breast cancer. Surg Oncol Clin N Am 19: 581-606.

7. Sotiriou C, Pusztai L (2009) Gene-expression signatures in breast cancer. N Engl J Med 360: 790-800.

8. Controlled trial of tamoxifen as adjuvant agent in management of early breast cancer (1983) Interim analysis at four years by Nolvadex Adjuvant Trial Organisation. Lancet 8319: 257-261.

9. Baum M, Brinkley DM, Dossett JA, McPherson K, Patterson JS, et al. (1983) Improved survival among patients treated with adjuvant tamoxifen after mastectomy for early breast cancer. Lancet 2: 450 .

10. Early Breast Cancer Trialists' Collaborative Group (2011) Relevance of breast cancer hormone receptors and other factors to the efficacy of adjuvant tamoxifen: patient-level meta-analysis of randomised trials. Lancet 9793: 771 84.

11. Howell A, Cuzick J, Baum M, Buzdar A, Dowsett M, et al. (2005) Results of the ATAC (Arimidex, Tamoxifen, Alone or in Combination) trial after completion of 5 years' adjuvant treatment for breast cancer. Lancet 9453: 60-2. 
Citation: Khan H, Anampa J (2016) The Evolving Adjuvant Treatment Landscape in Patients with Early Breast Cancer. Mol Biol 5: e121. doi:10.4172/2168-9547.1000e121

Page 4 of 4

12. Breast International Group 1-98 Collaborative (2005) A comparison of letrozole and tamoxifen in postmenopausal women with early breast cancer. $\mathrm{N}$ Engl $\mathrm{J}$ Med 26: 2747-57.

13. Foulkes WD, Smith IE, Reis-Filho JS (2010) Triple-negative breast cancer. N Engl J Med 363: 1938-1948.

14. Goss PE, Ingle JN, Martino S, Robert NJ, Muss HB, et al. (2003) A randomized trial of letrozole in postmenopausal women after five years of tamoxifen therapy for early-stage breast cancer. N Engl J Med. 19: 1793-1802.

15. Davies C, Pan H, Godwin J, Gray R, Arriagada R, et al. (2013) Long-term effects of continuing adjuvant tamoxifen to 10 years versus stopping at 5 years after diagnosis of oestrogen receptor-positive breast cancer: ATLAS, a randomised trial. Lancet 9869: 805-816.

16. Pagani O, Regan MM, Walley BA, Fleming GF, Colleoni M, et al. (2014) Adjuvant exemestane with ovarian suppression in premenopausal breast cancer. N Engl J Med 371: 107-118.

17. Pagani O, Regan MM, Francis PA; TEXT and SOFT Investigators; International Breast Cancer Study Group (2014) TEXT and SOFT Investigators; International Breast Cancer Study Group Exemestane with ovarian suppression in premenopausal breast cancer. N Engl J Med 371: 1358-1359.

18. Anampa J, Makower D, Sparano JA (2015) Progress in adjuvant chemotherapy for breast cancer: an overview. BMC Med 13: 195.

19. Fisher B, Ravdin RG, Ausman RK, Slack NH, Moore GE, et al. (1968) Surgical adjuvant chemotherapy in cancer of the breast: results of a decade of cooperative investigation. Ann Surg 168: 337-356.

20. Carter SK (1974) The chemical therapy of breast cancer. Semin Oncol 1: 131 144.

21. Early Breast Cancer Trialists' Collaborative Group (EBCTCG) (2012) Comparisons between different polychemotherapy regimens for early breast cancer: meta-analyses of long-term outcome among 100,000 women in 123 randomised trials. Lancet 9814: 432-44.

22. Bonadonna G, Brusamolino E, Valagussa $P$, Rossi $A$, Brugnatelli $L$, et al. (1976) Combination chemotherapy as an adjuvant treatment in operable breast cancer. N Engl J Med 294: 405-410.

23. Abrams JS (2001) Adjuvant therapy for breast cancer: results from the USA consensus conference. Breast Cancer 8: 298-304.

24. Fisher B, Brown AM, Dimitrov NV, Poisson R, Redmond C (1990) Two months of doxorubicin-cyclophosphamide with and without interval reinduction therapy compared with 6 months of cyclophosphamide, methotrexate, and fluorouracil in positive-node breast cancer patients with tamoxifen-nonresponsive tumors: results from the National Surgical Adjuvant Breast and Bowel Project B-15. J Clin Oncol 9: 1483-96.

25. Fisher B, Anderson S, Tan-Chiu E, Wolmark N, Wickerham DL, et al. (2001) Tamoxifen and chemotherapy for axillary node-negative, estrogen receptornegative breast cancer: findings from National Surgical Adjuvant Breast and Bowel Project B-23. J Clin Oncol, 4: 931-42.
26. Henderson IC, Berry DA, Demetri GD, Cirrincione CT, Goldstein LJ, et al. (2003) Improved outcomes from adding sequential Paclitaxel but not from escalating Doxorubicin dose in an adjuvant chemotherapy regimen for patients with node-positive primary breast cancer. J Clin Oncol 6: 976-83.

27. Swain SM, Jeong JH, Geyer CE Jr, Costantino JP, Pajon ER, et al. (2010) Longer therapy, iatrogenic amenorrhea, and survival in early breast cancer. $\mathrm{N}$ Engl J Med 362: 2053-2065.

28. Loprinzi CL, Ravdin PM (2003) Decision-making for patients with resectable breast cancer: individualized decisions for and by patients and their physicians. J Natl Compr Canc Netw 1: 189-196.

29. Sparano JA, Martino S, Ligibel J, Saphner T, Wolff AC, et al. (2014) Ten year update of E1199: Phase III study of doxorubicin-cyclophosphamide followed by paclitaxel or docetaxel given every 3 weeks or weekly in patients with axillary node-positive or high-risk node-negative breast cancer, in San Antonio Breast Cancer Symposium. 2014: San Antonio, TX

30. Wolff AC, Hammond MEH, Hicks DG, Dowsett M, McShane LM, et al. (2013) Recommendations for human epidermal growth factor receptor 2 testing in breast cancer: American Society of Clinical Oncology/College of American Pathologists clinical practice guideline update. J Clin Oncol 31: 3997-4013.

31. Romond EH, Perez EA, Bryant J, Suman VJ, Geyer CE Jr, et al. (2005) Trastuzumab plus adjuvant chemotherapy for operable HER2-positive breast cancer. N Engl J Med 353: 1673-1684.

32. Joensuu H, Kellokumpu-Lehtinen PL, Bono P, Alanko T, Kataja V, et al. (2006) Adjuvant docetaxel or vinorelbine with or without trastuzumab for breast cancer. N Engl J Med 354: 809-820.

33. Piccart-Gebhart MJ, Procter M, Leyland-Jones B, Goldhirsch A, Untch M, et al. (2005) Trastuzumab after adjuvant chemotherapy in HER2-positive breast cancer. N Engl J Med 353: 1659-1672.

34. Slamon D, Eiermann W, Robert N, Pienkowski T, Martin M, et al. (2011)Adjuvan trastuzumab in HER2-positive breast cancer. N Engl J Med 365: 1273-1283.

35. Pivot X, Romieu G, Debled M, Pierga JY, Kerbrat P, et al (2013) 6 month versus 12 months of adjuvant trastuzumab for patients with HER2-positive early breast cancer (PHARE): a randomised phase 3 trial. Lancet Oncol 14 741-748.

36. Goldhirsch A, Gelber RD, Piccart-Gebhart MJ, de Azambuja E, Procter M, et al. (2013) 2 years versus 1 year of adjuvant trastuzumab for HER2-positive breast cancer (HERA): an open-label, randomised controlled trial. Lancet 382 1021-1028.

37. Schneeweiss A, Chia S, Hickish T, Harvey V Eniu A (2013) Pertuzumab plus trastuzumab in combination with standard neoadjuvant anthracyclinecontaining and anthracycline-free chemotherapy regimens in patients with HER2-positive early breast cancer: a randomized phase II cardiac safety study (TRYPHAENA). Ann Oncol 24(9): 2278-84.

38. Early Breast Cancer Trialists' Collaborative (2015) Adjuvant bisphosphonate treatment in early breast cancer: meta-analyses of individual patient data from randomised trials. Lancet 386(10001): 1353-1361 